\title{
Transforming Organisations - (some) insights from complexity theory
}

\author{
Robert MacIntosh ${ }^{1}$, Donald MacLean ${ }^{1}$, Ian Arbon ${ }^{2}$ and \\ Gordon McGhee
}

1

University of Glasgow

Department of

Management Studies

53 - 59 Southpark Avenue

Glasgow

G12 8LF

tel. $\quad+1413305939$

fax. $\quad+1413305669$
2

Peter Brotherhood Ltd $\quad$ D McGhee \& Sons Ltd Werrington Parkway 19 Murano Street

Peterborough Firhill

PE4 5HG Glasgow G20 7RQ

England

tel. $+1733292200 \quad$ tel. +1419461199

fax. $+1733292302 \quad$ fax. +1419461660

\begin{abstract}
This paper presents an approach to organisational transformation which was developed by action research. Complexity Theory is used as the theoretical basis for transformation model called Conditioned Emergence and two industrial applications of this model are described. The paper also describes the research process which produced the model, relating it to Soft Systems Methodology.
\end{abstract}

\section{Keywords}

Organisational Transformation, Complexity Theory, Soft Systems Methodology, Action Research, Organisational Learning, Business Process Re-engineering 


\subsection{Organisational Transformation}

Organisational transformation has become the subject of increasing managerial attention in recent years. There are several possible, and plausible, explanations for the growing interest in transformation. Increasing competition, the impact of computing and telecommunications developments, globalisation, the shift to a new information or knowledge based economy - or some combination of these. Some organisations have been forced into major transformation processes by external pressures, others have initiated the transformation process themselves.

A number of approaches have been introduced as the definitive way to re-invent your organisation - e.g. TQM, JIT, BPR, Organisational Learning. There have been mixed results with each of these approaches. The literature is scattered with some spectacular success stories as well as surveys which indicate worrying failure rates. We have been involved in an action research process in an effort to understand why some organisations seem to undergo successful transformation processes while others fail to disentangle themselves from their current mode of operation.

\subsection{Research Methodology}

In this paper we present two case studies of organisational transformation. We will discuss the development of a quasi-prescriptive model to guide the transformation process in these case studies. In working on the case studies we made an explicit decision to become actively involved in the transformation processes being experienced within the organisations. This meant that we were undertaking a form of action research and we have therefore chosen to use Checkland's Soft Systems Methodology (SSM) to explain the research process which generated the model presented later in the paper (see Checkland and Scholes, 1990).

\section{D McGHEE \& SONS LTD}

The first case study did indeed present us with "a real world situation of concern," as indicated in Figure 1. D McGhee and Sons Ltd were a third generation family business operating in a mature market. Although buoyant for much of its existence, recent years had brought a downturn in company performance. Demand for many of its traditional products was declining. Organised along traditional command-and-control lines, management processes and structures had remained largely unchanged for several decades and the organisation had struggled to respond to a worsening competitive climate which had seen a number of its major competitors disappear in the past 3 years. Demand for many of its traditional products was declining and a failure to introduce new 
products in recent years meant that many orders had been secured on the basis of price or historical relationships and margins had shrunk to the point where longterm viability was now in question.

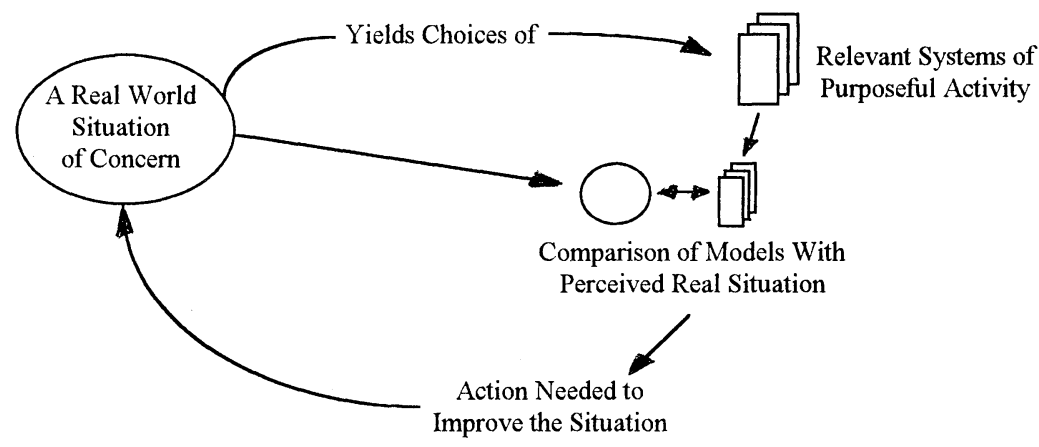

Figure 1

The Basic Shape of Soft Systems Methodology

In Soft System terms, we began the first case study with the intention of applying a combination of techniques from business process re-engineering and organisational learning as they seemed to offer solutions relevant to the organisation's situation.

\subsection{Business Process Re-engineering}

BPR emerged in the early 1990 s as a management technique which used the power of IT to enable new ways of managing and operating businesses. The main proponents of BPR claim that organisations adopted functional structures which were appropriate when they were originally introduced but which artificially subdivide business processes so that no-one was responsible for the performance of the complete process. (see Hammer and Champy, 1993 for example).

From its introduction in 1990, BPR's popularity grew rapidly. However, it is now widely accepted that the majority of business process projects fail to live up to expectations. One of the originators of the concept, Tom Davenport, has stated that he believes the issue of failure rates to be a red herring (Davenport 1995). Indeed, BPR might be thought of as following an established pattern of poor implementation, a recent survey indicated that $85 \%$ of companies using TQM had been disappointed with the results (Oates 1993).

BPR can be a powerful tool for breaking with historical working practices and promises to deliver radical improvements in performance. It therefore seemed an obvious choice of technique to apply to D McGhee \& Sons. 


\subsection{Organisational Learning}

Organisational Learning $(\mathrm{OL})$ is a label applied to a range of techniques, concepts and approaches which can be used to transform organisations. The pioneering work of Argyris and Schon (1978) describes organisations as reacting to new situations by habitually enacting defensive routines. These defensive routines are widely accepted, if often inappropriate, responses that were extremely successful at some stage in the past. Routines are an important part of organisational life and to some extent act as the organisation's memory or the repository of past learning. They become dangerous when repeated use of the same routine institutionalises it to the point where it is applied even when the environment is radically different. Long term survival requires organisations to avoid competency traps by periodically stepping out of smooth running routines which have been created and reinforced by past successes. Innovation lies in the exceptions not the routines but there is a risk associated with this. These concepts, popularised by Senge (1990), also seemed applicable to McGhees.

\subsection{Developing the Conditioned Emergence Model}

Our work with McGhees involved both the directors and managers in the organisation. We began by using OL techniques to get the directors to articulate their objectives and goals for the organisation. Using workshops, outdoor and indoor exercises and simulations we developed a collective view of the unwritten rules binding behavioural norms and expectations within the organisation as it then operated. We then worked on a shared vision of the kind of organisation the directors wanted McGhees to become. This process surfaced a number of conflicting assumptions about the organisation which individual directors had held but not shared with their colleagues.

A new set of groundrules, which would govern behaviour in this new organisation, were developed. The directors then constructed specific projects on which they, and the managers, would work over a 12 month period. These projects covered new product development, production improvements and organisational development.

After some progress had been made in each of these areas, it became obvious that the project teams were either running out of steam or running up against organisational barriers which were hampering their progress. At this point we began to reassess the approach we had taken and to look for an explanation of what had happened. We began to experiment with models from complexity theory in our search for explanations of how new order arises from turbulent, far from equilibrium situations. In particular, we believed that the concept of dissipative structures might offer an explanation of what was happening in the organisation. 


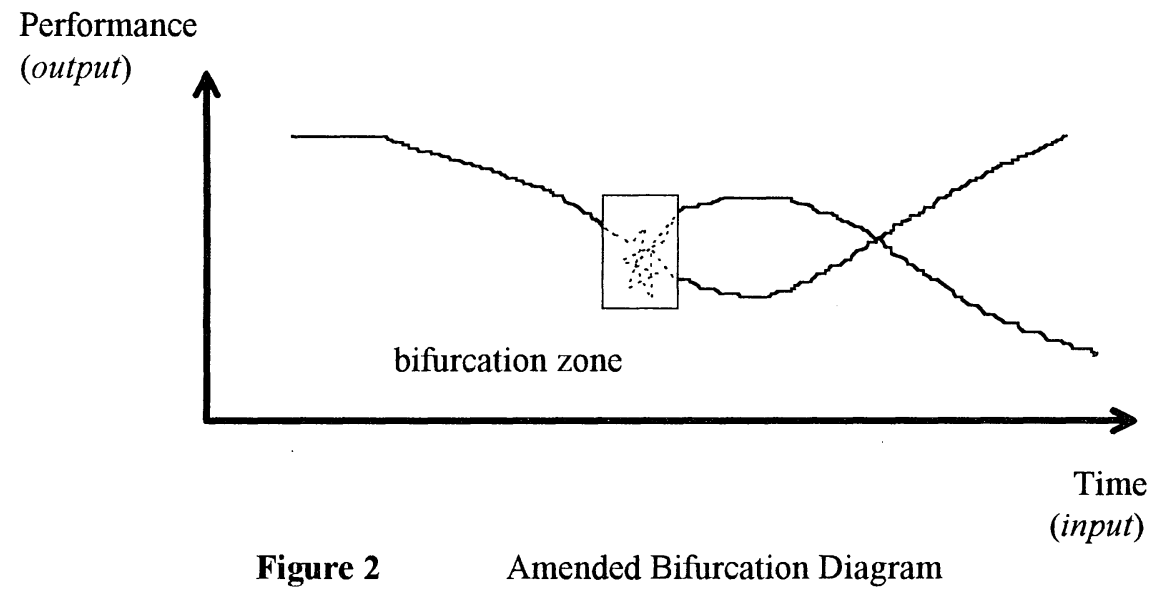

Figure 2 shows the bifurcation process associated with a dissipative structure (see Leifer, 1989 for a more detailed explanation). It depicts a system where the level of performance deteriorates until a crisis is reached and the system itself becomes unstable. At this point the system becomes open to its environment, importing energy and exporting entropy (a measure of disorder) as a new structure takes shape in accordance with the operations of a set of simple order-generating rules. Since, in physics, heat is the most entropic form of energy, the system is said to be a dissipative structure because the entropy exportation is characterised by heat loss.

As the system reaches the crisis point in figure 2, two possible future trajectories extend into the future. In systems studies by natural scientists, the random application of positive feedback to small signals then determine which trajectory will eventually be followed.

In translating this model to the process of organisational transformation we began to understand what had been happening in McGhees. The two sets of underlying rules which we had identified as characterising the existing organisation and the desired organisation were associated with the two trajectories shown in figure 2. As the organisation attempted to transform to its desired future state, established routines were enacted which exerted pressure to revert to tried and tested methods. This appeared to have choked off the transformation process. In other words, negative feedback acting on the existing rules prevented the operation of positive feedback on the new ones.

As predicted by Soft Systems Methodology, some practical experience had yielded a new choice of relevant models. Complexity theory had provided us with the insight that new order emerges in far from equilibrium conditions. This led us to 
construct a three stage model for transformation which we called Conditioned Emergence (MacLean and MacIntosh, 1997). The three stages are as follows:

\section{Conditioning}

Prior to transformation, the organisation must identify and reframe the rules which underpin its current form. By the end of this stage the rules, around which the new organisational form will emerge, are in place.

\section{Creating Far-From-Equilibrium Conditions}

Having done the conditioning work, the organisation must move to far from equilibrium conditions in order to create space for the new structure to take hold. The onset of a crisis, either real or precipitated, is required. This often takes the form of restructuring or changes to roles and responsibilities. While the organisation resides in such unfamiliar territory it typically becomes more open, often developing a capacity to import energy and export entropy i.e. it becomes dissipative. During this period, the new order based on the new rules developed in stage 1 will seek to impose itself.

\section{Managing the Feedback Processes}

As the new organisation begins to emerge from the transformation process, positive and negative feedback must be applied as appropriate. Traces of the old organisation will inevitably remain and there will be pressure to revert to tried and tested methods. The key managerial task is to resist this pressure while looking for small signals consistent with the rules structure agreed in stage 1 . Anything which reinforces the new rules should be encouraged in order that the effects may be amplified encouraging the new organisational form to take hold. The organisation will be somewhat unstable at this point as the old and new forms compete with each other. This will be particularly true at the outset since reverting to tried and tested methods would probably produce improved performance in the short term if the organisation were to push the old systems harder.

We used the Conditioned Emergence model with McGhees and a restructuring exercise, which involved departures at both managerial and directorial levels, eventually created far from equilibrium conditions. Following this restructuring exercise, the organisation was able to break from its established routines and begin what became a successful transformation process.

\section{PETER BROTHERHOOD LTD}

The second case study involves Peter Brotherhood, a company which was established in 1867 to make a range of heavy mechanical products. In the last 30 years the organisation has shrunk from 2500 people to 230 and now buys many 
components and sub-assemblies which would traditionally have been manufactured in-house. Following a poor financial performance over a number of years, the senior management team was overhauled with only one of the original team remaining. The organisation is using the Conditioned Emergence model to inform the transformation process it is undergoing.

\subsection{Conditioning}

Using a similar process to that used with McGhees, the management team from Peter Brotherhood agreed a new rule set which would characterise the kind of organisation which they wanted to become. They also identified the defensive routines which they expected to encounter while attempting to transform the organisation. These are summarised in table 1.

\begin{tabular}{|l|l|}
\hline \multicolumn{1}{|c|}{ New Rules } & \multicolumn{1}{|c|}{ Defensive Routines } \\
\hline kill cynicism & $\begin{array}{l}\text { blame anything and everything for not } \\
\text { getting orders } \\
\text { change }\end{array}$ \\
$\begin{array}{l}\text { don't jump to conclusions; identify real } \\
\text { causes and act accordingly } \\
\text { support each other - take a genuine interest } \\
\text { in other peoples' problems } \\
\text { and it didn't work } \\
\text { be honest, considerate and flexible }\end{array}$ & $\begin{array}{l}\text { hit soft targets first } \\
\text { I didn't know that no-one tells me } \\
\text { anything }\end{array}$ \\
\hline
\end{tabular}

Table 1 New Rules and Defensive Routines at Peter Brotherhood Ltd

\subsection{Creating Far From Equilibrium Conditions}

At the time of writing, we are currently assessing the options for moving the organisation to far from equilibrium conditions. This will almost certainly involve changes to processes and procedures, as well as roles and responsibilities. It is therefore imperative that the management team consider their options carefully. The management team have to be prepared to encourage the application of the new rules while remaining conscious of the temptation to enact defensive routines.

\section{CONCLUSIONS}

The conclusions of this paper come under two categories, those relating to the content of the research and those relating to the process by which the research is being conducted. 


\subsection{Conclusions on Organisational Transformation}

Our work has led us to believe that complexity theory has a number of valuable contributions to make to research on organisational transformation. Conditioned Emergence model, based on the complexity concept of dissipative structures, provides a quasi-prescriptive framework for transformation processes. It reconciles the need for managerial control with the possibility of emergent phenomena.

\subsection{Conclusions on SSM \& Action Research}

Given that management is an applied discipline, we believe that action research is the only realistic way to access the rich, complex patterns of activities which make up organisational life. It has only been through actively participating in real transformation projects that we have been able to develop models which are both theoretically grounded and practically useful. Checkland's SSM links theory building and practical application into a form of learning cycle.

\section{REFERENCES}

Argyris, C. and Schon, D.A. (1978) Organisational Learning: a theory of action perspective, Addison Wesley, Reading - Massachusetts

Checkland, P. and Scholes, J. (1990) Soft Systems Methodology in Action, John Wiley and Sons, Chichester, England

Davenport, T.H. (1995) 'Re-engineering Perceptions,' Informationweek, Issue 518, 13 March 1995, p 90

Hammer, M. and Champy, J. (1993) Re-engineering the Corporation - a manifesto for business revolution, Nicholas Brealey Publishing Ltd

Leifer, R. (1989) 'Understanding Organisational Transformation Using A Dissipative Structures Model,' Human Relations, 42 (10), pp 899 - 916

MacLean, D. and MacIntosh, R. (1997) 'Conditioned Emergence: an approach to transformation using business process re-engineering and organisational learning,' Invited Paper, Proceedings of the Business Process Track at the British Academy of Management Conference, 8 - 10 September 1997, pp 95 - 118

Oates, D. (1993) 'Buzzwords: learning the language of business,' Accountancy, 112 (1200), p 38

Senge, P. (1990) The Fifth Discipline: the art and practice of the learning organisation, Currency/Doubleday, New York

\section{BIOGRAPHIES}

Robert MacIntosh and Donald MacLean are both lecturers at the University of Glasgow. They jointly run a small unit called The Success Cycle which performs action research on organisational transformation and the managerial implications of complexity theory. Gordon McGhee and Ian Arbon are the managing directors of D McGhee \& Sons Ltd and Peter Brotherhood Ltd, respectively. 